\title{
Quantitative 3-tesla multiparametric MRI in differentiation between renal cell carcinoma subtypes
}

\author{
Ali Elsorougy ${ }^{1 *}$, Hashim Farg ${ }^{1}$, Dalia Bayoumi², Mohamed Abou El-Ghar ${ }^{1}$ and Magda Shady ${ }^{2}$
}

\begin{abstract}
Background: MRI provides several distinct quantitative parameters that may better differentiate renal cell carcinoma (RCC) subtypes. The purpose of the study is to evaluate the diagnostic accuracy of apparent diffusion coefficient (ADC), chemical shift signal intensity index (SII), and contrast enhancement in differentiation between different subtypes of renal cell carcinoma.

Results: There were 63 RCC as regard surgical histopathological analysis: 43 clear cell (ccRCC), 12 papillary (pRCC), and 8 chromophobe (cbRCC). The mean ADC ratio for $\operatorname{ccRCC}(0.75 \pm 0.13)$ was significantly higher than that of $\operatorname{pRCC}(0.46 \pm 0.12, P<0.001)$ and $\operatorname{cbRCC}(0.41 \pm 0.15, P<0.001)$. The mean ADC value for $\operatorname{CCRCC}(1.56 \pm 0.27 \times$ $\left.10^{-3} \mathrm{~mm}^{2} / \mathrm{s}\right)$ was significantly higher than that of pRCC $\left(0.96 \pm 0.25 \times 10^{-3} \mathrm{~mm}^{2} / \mathrm{s}, P<0.001\right)$ and $\mathrm{cbRCC}(0.89 \pm$ $\left.0.29 \times 10^{-3} \mathrm{~mm}^{2} / \mathrm{s}, P<0.001\right)$. The mean SII of pRCC $(1.49 \pm 0.04)$ was significantly higher than that of cCRCC $(0.93$ $\pm 0.01, P<0.001)$ and $\operatorname{cbRCC}(1.01 \pm 0.16, P<0.001)$. The ccRCC absolute corticomedullary enhancement $(196.7 \pm$ 81.6) was significantly greater than that of $\operatorname{cbRCC}(177.8 \pm 77.7, P<0.001)$ and $\mathrm{pRCC}(164.3 \pm 84.6, P<0.001)$.
\end{abstract}

Conclusion: Our study demonstrated that multiparametric MRI is able to afford some quantitative features such as ADC ratio, SII, and absolute corticomedullary enhancement which can be used to accurately distinguish different subtypes of renal cell carcinoma.

Keywords: Quantitative, Multiparametric, MRI, RCC, Subtypes

\section{Background}

Preoperative histopathological classification of renal cell carcinoma (RCC) is usually carried out by invasive percutaneous biopsy. Nowadays, many authors have reported the promising value of imaging in non-invasive characterization of different subtypes of RCC [1].

Multiparametric (MP) MRI is rapidly becoming the reference standard for renal MRI as it has a good accuracy in characterization of renal masses. The evaluation of the renal tumor subtypes utilizing some parameters of MRI could be beneficial for the protocol of management [2].

\footnotetext{
* Correspondence: Ali_sorougy@hotmail.com

1 Radiology Departments, Urology and Nephrology Center, Mansoura University, Mansoura, Egypt

Full list of author information is available at the end of the article
}

Clear cell RCC is the most common subtype of RCC, accounting for $65-80 \%$ of cases. Clear cell carcinomas are associated with a less favorable outcome than both papillary and chromophobe RCC subtypes, with a 5-year survival rate of $44-69 \%$ [3].

Characterization of renal masses is helpful for identifying renal masses requiring surgery, without further investigation with biopsy from those require ablation or active surveillance, MRI appears to be principally effective if considering a multiparametric approach [1].

Chemical shift imaging is based on differences in the inherent magnetic field experienced by the protons in fat molecules in comparison to those in the molecules of water, which are caused by the effects of the non-proton components of the molecules (carbon versus oxygen, 
respectively) on the electron cloud that surrounds the protons $[4,5]$.

Diffusion of tissues (Brownian motion) can be measured utilizing particularly designed DWI sequences. The SI in DWI depends on specific b operation factor and a specific factor concerning tissue, ADC [6]. The $b$ value designates how much diffusion weighting is practical. A low $b$ value is related to high SI while a high $b$ value designates an elevated level of contrast of the tissue. Masses with diffusion restriction appear hyperintense in DWI and of low SI in the ADC map [7].

DWI allows for determination of renal masses whether of cystic nature or solid depends on their degree of water movement restriction, which is useful in cases with contrast injection contraindication. A mass that still of high SI on images of high $b$ value and of low ADC value is suggesting of solid component [8]. On the other hand, hemorrhagic content of non-neoplastic nature inside cystic lesion may show diffusion restriction. In spite of some using the ADC values to differentiate between benign and malignant lesions and RCC subtyping which was done by some authors [9], significant overlap in these findings is present and DWI is not applied as definitive as DCE imaging [10].

Dynamic contrast-enhanced MRI (DCE-MRI) is used to assess contrast material kinetics within a tumor, reflecting the vascularity of the tissue [11].

Enhancing pattern of a mass after the injection of contrast agent is the most beneficial tool to differentiate solid and cystic masses [12]. Cystic mass pattern of enhancement can discriminate solid components from debris. Post-contrast T1WI is useful in determination of the pattern of enhancement and its intensity, so this plays useful differentiating role among the 3 common RCC subtypes [13].

The 3-tesla systems of MRI, phased array coils of high-density, advanced sequences, like multi-echo Dixon
(mDIXON) affords high-quality images and perfect spatial-resolution. The $3 \mathrm{~T}$ machines provide benefit of great signal-to-noise ratio, which is helpful in shortening the time acquisition and/or produce high resolution of images [14].

We hypothesized that quantitative parameters of MRI can accurately differentiate renal cell carcinoma subtypes. So, we conducted this study to assess the diagnostic performance of apparent diffusion coefficient, chemical shift signal intensity index, and dynamic contrast enhancement parameters in differentiation among different subtypes of renal cell carcinoma.

\section{Methods}

\section{Subjects}

This prospective study was conducted upon 63 consecutive patients between October 2017 and October 2019. Patients were referred from the outpatient clinic of the Urology Department to our department of radiodiagnosis, in the same center. Institutional board of ethics had approved this study and an informed consent was obtained from each patient subsequent to complete clarification of the profits and the dangers of the procedures. No further apparent risks to the patients who were included in this study.

Patients were selected according to the following criteria:

- Inclusion criteria: Adult patients (older than 18 years) with solid parenchymal renal masses diagnosed by US or CT.

- Exclusion criteria: Patients with general contraindications for MR examination (as with pacemaker or metallic prosthesis), patients with high renal function tests, not suitable for IV-gadolinium injection, and patients refusing consent.

Table 1 Mean values of different quantitative multiparametric MRI parameters in the current study

\begin{tabular}{|c|c|c|c|c|c|c|c|c|c|}
\hline Subtype & & $\begin{array}{l}\text { Absolute CM } \\
\text { enhancement }\end{array}$ & $\begin{array}{l}\text { Absolute NG } \\
\text { enhancement }\end{array}$ & $\begin{array}{l}\text { Relative } \\
\text { CM } \\
\text { enhancement }\end{array}$ & $\begin{array}{l}\text { Relative } \\
\text { NG } \\
\text { enhancement }\end{array}$ & $\begin{array}{l}\text { Absolute } \\
\text { washout }\end{array}$ & $\begin{array}{l}\text { ADC value of } \\
\text { the lesion }\end{array}$ & $A D C_{\text {ratio }}$ & SII \\
\hline \multirow[t]{3}{*}{ ccRCC } & Mean & 196.7 & 185.1 & 39.9 & 35.6 & 20.5 & $1.56 \times 10^{-3}$ & 0.75 & 0.93 \\
\hline & $N$ & 43 & 43 & 43 & 43 & 43 & 43 & 43 & 43 \\
\hline & Std. & 81.6 & 59.9 & 37.2 & 21 & 33 & 0.27 & 0.13 & 0.01 \\
\hline \multirow[t]{3}{*}{ pRCC } & Mean & 164.3 & 113.9 & -6.1 & -28.2 & 50.4 & $0.96 \times 10^{-3}$ & 0.46 & 1.49 \\
\hline & $N$ & 12 & 12 & 12 & 12 & 12 & 12 & 12 & 12 \\
\hline & Std. & 84.60 & 58.44 & 38.24 & 10.04 & 46.82 & 0.25 & 0.12 & 0.04 \\
\hline \multirow[t]{3}{*}{$\mathrm{cbRCC}$} & Mean & 177.8 & 160.1 & 96 & 49.25 & 30.25 & $0.89 \times 10^{-3}$ & 0.41 & 1.01 \\
\hline & $N$ & 8 & 8 & 8 & 8 & 8 & 8 & 8 & 8 \\
\hline & Std. & 77.7 & 7.8 & 78.5 & 10.2 & 73.2 & 0.29 & 0.15 & 0.16 \\
\hline
\end{tabular}



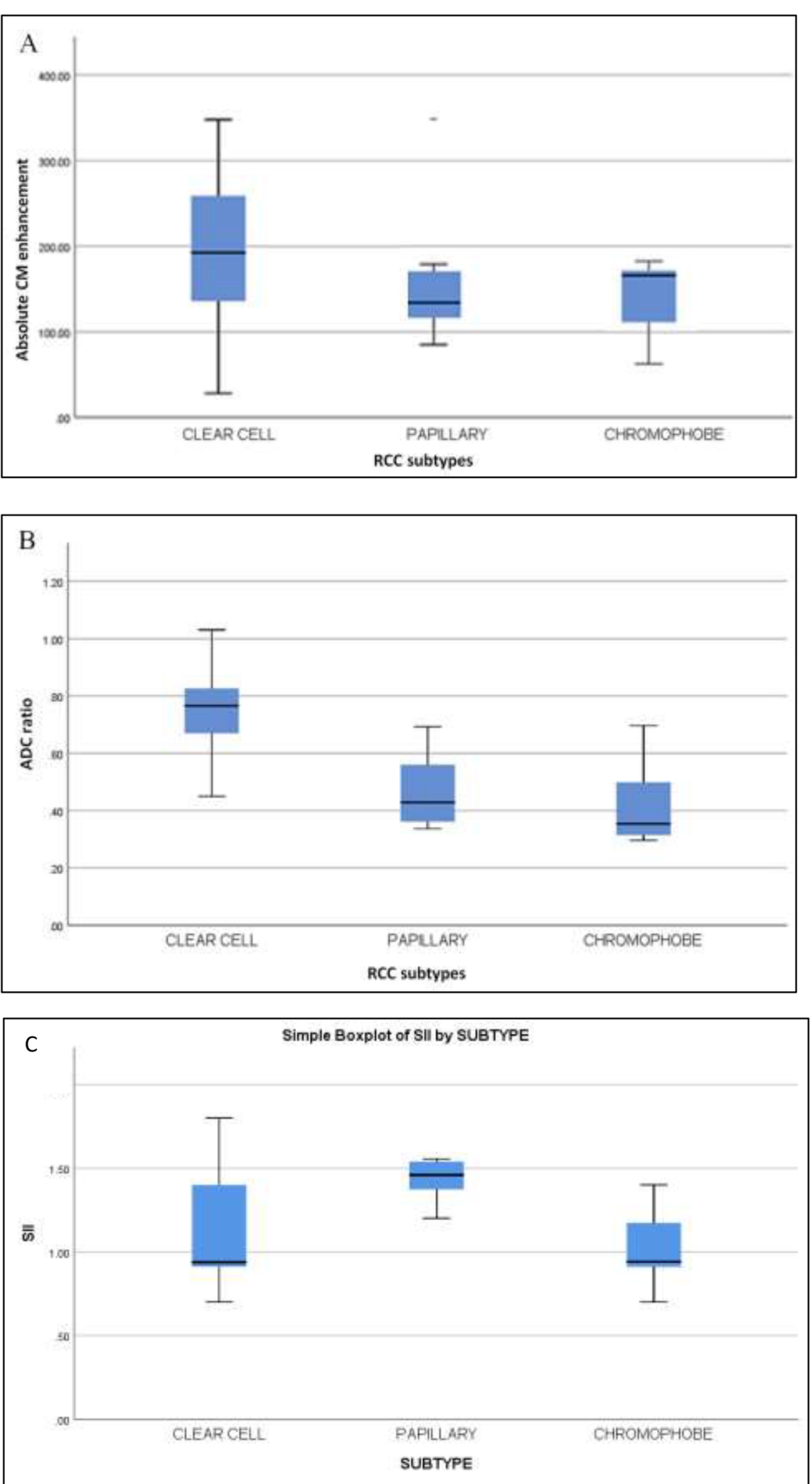

Fig. 1 Box plots show multiparametric quantitative evaluation of the subtypes of renal masses. a Absolute CM enhancement, $\mathbf{b}$ ADC ratio, and c Sll are shown 
Table 2 AUC, optimal cutoff values, and corresponding performances of dynamic parameters for differentiation between clear cell RCC and non-clear cell RCC lesions

\begin{tabular}{lllll}
\hline Variables & AUC & Cutoff value & Sensitivity & Specificity \\
\hline Absolute CM enhancement & 0.937 & 182 & $91.7 \%$ & $74.4 \%$ \\
Absolute NG enhancement & 0.787 & 156.5 & $83.3 \%$ & $76.7 \%$ \\
Relative CM enhancement & 0.779 & 18 & $75 \%$ & $88.4 \%$ \\
Relative NG enhancement & 0.677 & 15 & $83.3 \%$ & $67.4 \%$ \\
Absolute washout & 0.256 & 111 & $83.3 \%$ & $67.4 \%$ \\
\hline
\end{tabular}

\section{MRI technique}

All the patients underwent multiparametric MRI examination done by using 3 Tesla MRI scanner (Phillips, Ingenia $3 \mathrm{~T}$, Best, The Netherlands). Imaging will be in the supine position using phased-array body coil using M-Dixon program and was include these sequences:

\section{Axial chemical shift (IP + OP)}

Dual echo CSI gradient recall T1W images were taken at IP and OP echo times with 6-8 mm thickness of slice, approximating matrix size of $256 \times 320,3 \mathrm{~mm}$ thickness of slice, and opposed-phase echo time.

Axial T2-weighted imaging is done with time repetition $2112 \mathrm{~ms}$, echo time $100 \mathrm{~ms}$, flip angle 90 degrees, field-of-view $32 \mathrm{~cm}$, matrix size $268 \times 344 \mathrm{~mm}$, slice thickness $5 \mathrm{~mm}$, slice gap $0-0.4 \mathrm{~mm}$, and excitations number is $2-3$.

\section{Fat-suppressed T1W sequences and DCE}

Imaging before and after IV bolus administration of 0.1 $\mathrm{mmol} / \mathrm{kg}$ of (Dotarem) (gadoteric acid) by rate of $2 \mathrm{~mL} /$ s, and after that giving saline flush. (nonenhanced and gadolinium-enhanced DCE sequences: corticomedullary timed empirically at $35 \mathrm{~s}$, followed nephrographic at 120 $\mathrm{s}$, and excretory phases), time repetition $182 \mathrm{~ms}$, echo time $4.6 \mathrm{~ms}$, flip angle 70 degrees, field of view $37 \mathrm{~cm}$, matrix size $220 \times 284 \mathrm{~mm}$, slice thickness $5 \mathrm{~mm}$, slice gap $0-0.4 \mathrm{~mm}$, and excitations number is 1 .

\section{DWI}

DWI was done in axial fat-saturated water-excited single-shot spin-echo with b value $\left(0,800 \mathrm{~s} / \mathrm{mm}^{2}\right)$, time repetition $1500 \mathrm{~ms}$, echo time $76 \mathrm{~ms}$, flip angle 90 degrees, field of view $40 \mathrm{~cm}$, matrix size $180 \times 194 \mathrm{~mm}$, slice thickness $5 \mathrm{~mm}$, slice gap $0.3-0.4 \mathrm{~mm}$, and excitations number is $4-10$.

\section{Quantitative analysis of MRI}

Quantitative data were measured for 3 parameters: ADC, SI index (SII), and contrast enhancement (CE). We place the ROI at the slice of maximum diameter and maximum solid component. We take care to not include
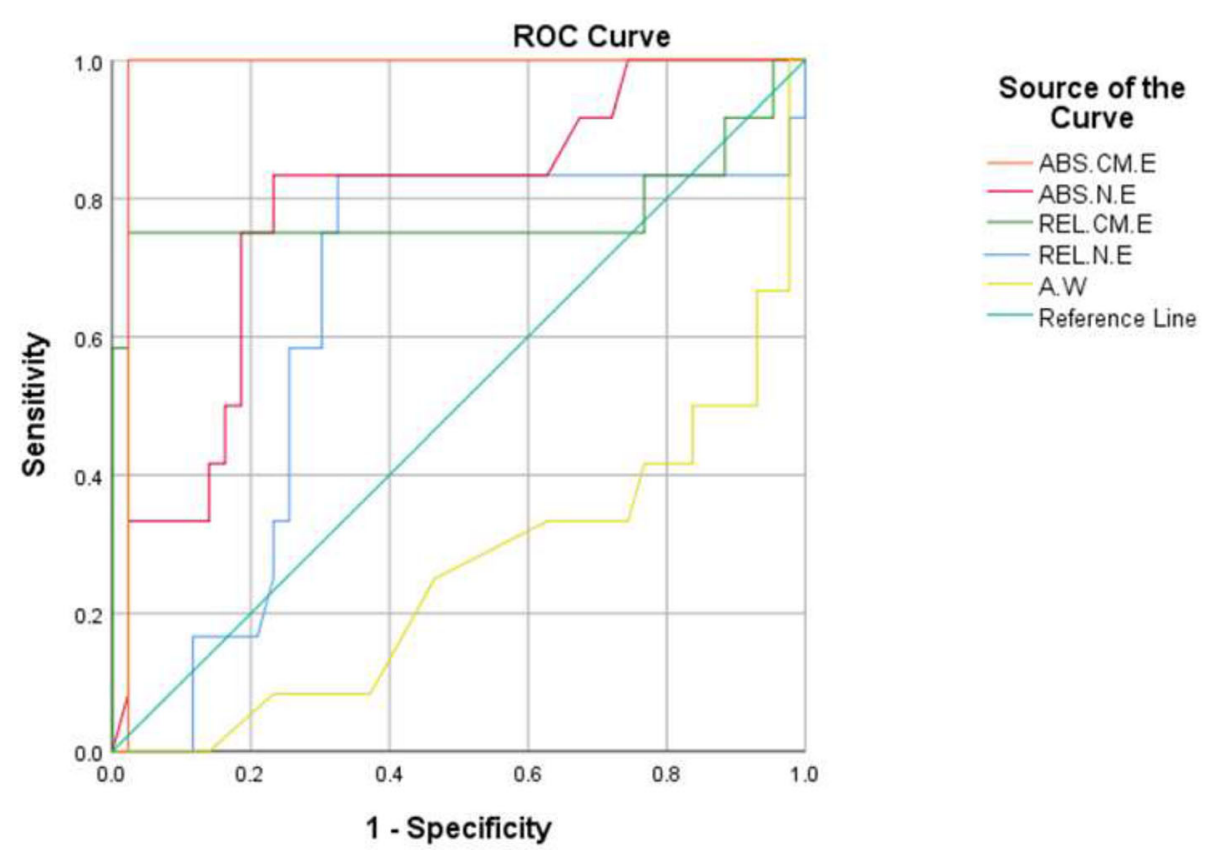

- Specificity

Fig. 2 ROC curves for parameters of dynamic study in differentiation between clear cell RCC and non-clear cell RCC lesions 
Table 3 AUC, optimal cutoff values, and corresponding performances of $A D C$ value and $A D C$ ratio for differentiation between clear cell RCC and non-clear cell RCC lesions

\begin{tabular}{lllll}
\hline Variables & AUC & Cutoff value & Sensitivity & Specificity \\
\hline ADC lesion $\left(\times \mathbf{1 0}^{-3}\right)$ & 0.936 & 1.35 & $91.7 \%$ & $76.7 \%$ \\
ADC ratio & 0.938 & 0.64 & $91.7 \%$ & $81.4 \%$ \\
\hline
\end{tabular}

any surrounding measurements and to avoid areas of cystic degeneration if it is found. ROI is drawn independently on images in each sequence to account for slight patient movement and differences in breathing between sequences and phases.

We measured the ADC mean, IP SI, OP SI, precontrast SI, CM-phase SI, and NG-phase SI. ADC mean of the same side non-lesion kidney was measured. We also measured precontrast enhancement, CM enhancement, and NG enhancement of non-lesion cortex of the same side.

The following calculations were performed for each lesion:

1. $\mathrm{ADC}$ ratio $=\mathrm{ADC}$ mean lesion $/ \mathrm{ADC}$ mean ipsilateral kidney.

2. Signal intensity index $=$ in phase-opposed phase.

3. Absolute corticomedullary enhancement $=$ corticomedullary lesion-precontrast lesion.

4. Absolute nephrographic enhancement = nephrographic lesion-precontrast lesion.
5. Relative corticomedullary enhancement $=$ corticomedullary lesion-corticomedullary nonlesion cortex.

6. Relative nephrographic enhancement $=$ nephrographic lesion-nephrographic non-lesion cortex.

7. Absolute washout $=$ corticomedullary lesion -nephrographic lesion.

\section{Pathological analysis}

Histopathological diagnosis was available after surgical excision of all included renal tumors.

\section{Statistical analysis}

Descriptive statistics (mean and percent and frequencies) were utilized to represent the collected data of the results. The evaluation of the differences between malignant and benign masses in the kidney or between specific comparisons of the subtype was carried out utilizing $t$ tests or Wilcoxon rank tests, as suitable. Multivariable logistic regression with backward stepwise selection was utilized to recognize predictors of malignant tumors. The level of significance was determined to be at $(P \leq 0.05)$ for the current study. Analyses were carried out using SPSS 23.0 (Chicago, IL, USA) for the Windows software.
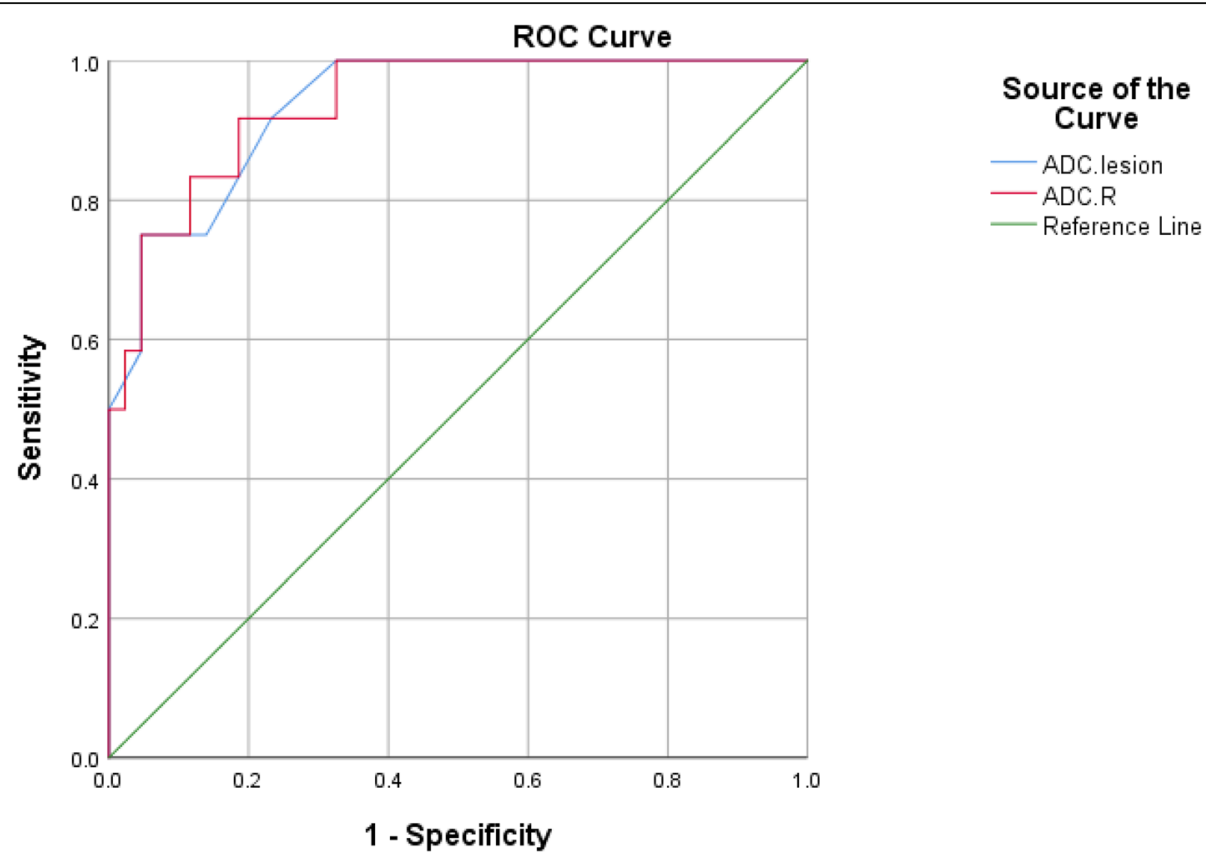

Diagonal segments are produced by ties.

Fig. 3 ROC curves for ADC value and ADC ratio in differentiation between clear cell RCC and non-clear cell RCC 
Table 4 AUC, optimal cutoff values, and corresponding performances of SII for differentiation between clear cell RCC and non-clear cell RCC lesions

\begin{tabular}{lllll}
\hline Variables & AUC & Cutoff value & Sensitivity & Specificity \\
\hline SII & 0.635 & 0.97 & $97.7 \%$ & $60 \%$ \\
\hline
\end{tabular}

\section{Results}

This prospective study included 63 patients (38 male and 25 female) with 63 histologically confirmed renal cell carcinomas. The mean age of patients was 68.2 years (range, 43-84 years). There were 43 clear cell RCCs (68.3\%), 12 papillary RCCs (19\%), and 8 chromophobe RCCs (12.7\%). No significant differences were observed either for age $(P=0.81)$ or sex $(P=0.34)$.

The mean ADC value for ccRCC $\left(1.56 \pm 0.27 \times 10^{-3}\right.$ $\left.\mathrm{mm}^{2} / \mathrm{s}\right)$ was significantly higher than that of pRCC $(0.96$ $\left.\pm 0.25 \times 10^{-3} \mathrm{~mm}^{2} / \mathrm{s}, P<0.001\right)$ and $\operatorname{cbRCC}(0.89 \pm 0.29$ $\left.\times 10^{-3} \mathrm{~mm}^{2} / \mathrm{s}, P<0.001\right)$. The mean ADC ratio for ccRCC $(0.75 \pm 0.13)$ was significantly higher than that of pRCC $(0.46 \pm 0.12, P<0.001)$ and cbRCC $(0.41 \pm 0.15$, $P<0.001)$. However, both ADC ratio and ADC value demonstrated no significant difference between pRCC and cbRCC with $P$ values were 0.997 and 0.56 . The mean SII of pRCC $(1.49 \pm 0.04)$ was significantly higher than that of ccRCC $(0.93 \pm 0.01, P<0.001)$ and cbRCC (1.01 $\pm 0.16, P<0.001)$. In addition, SII shows significant difference between $\mathrm{ccRCC}$ and $\operatorname{cbRCC}(P=$ 0.015). Regarding the dynamic MRI parameters, the absolute corticomedullary enhancement was the only statistically useful parameter in differentiation between clear and non-clear RCC subtypes. The mean ccRCC absolute CM enhancement $(196.7 \pm 81.6)$ was significantly greater than that of $\operatorname{cbRCC}(177.8 \pm 77.7, P<0.001)$ and pRCC $(164.3 \pm 84.6, P<0.001)$. However, absolute CM enhancement showed no significant difference between cbRCC and pRCC $(P=0.889)$, as shown in Table 1 and Fig. 1 .

\section{ROC curve analyses}

The cutoff value of absolute corticomedullary enhancement in differentiation between clear cell RCC and nonclear cell RCC lesions was 182 with AUC of 0.937, sensitivity of $91.7 \%$, and specificity of $74.4 \%$. Absolute corticomedullary enhancement had the highest AUC value compared to other dynamic MRI parameters (Table 2 and Fig. 2).

The cutoff value of ADC in differentiation between clear cell RCC and non-clear cell RCC was $\left(1.35 \times 10^{-3}\right)$ with AUC of (0.936), sensitivity of $91.7 \%$ and specificity of $76.7 \%$. However, the ADC ratio demonstrates cutoff value (0.64) with AUC of 0.938 , sensitivity of $91.7 \%$, and specificity of $81.4 \%$. There was no significant difference in AUC values in both parameters (Table 3 and Fig. 3).

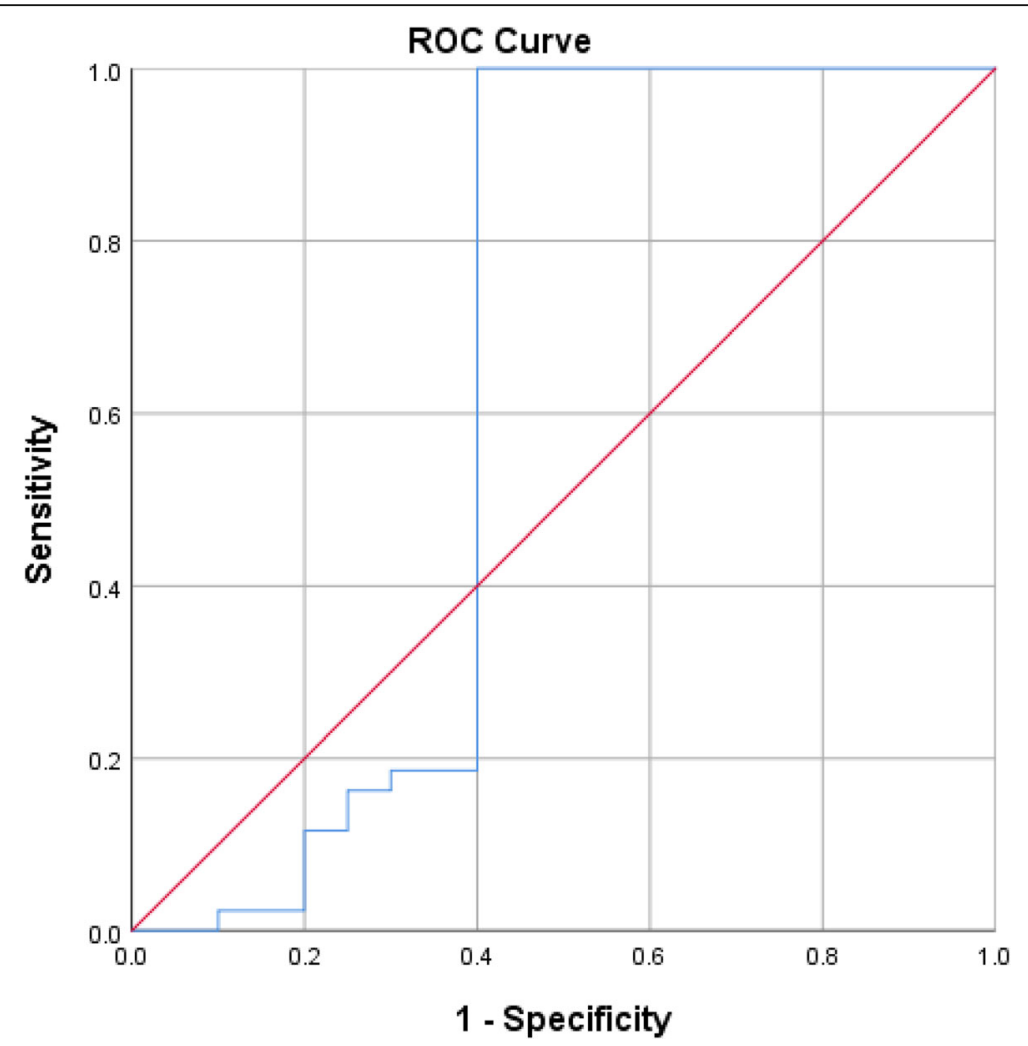

Fig. 4 ROC curve for signal intensity index in differentiation between clear cell RCC and non-clear cell RCC 
The cutoff value of SII in differentiation between clear cell RCC and non-clear cell RCC was 0.97 with AUC of 0.635 , sensitivity of $97.7 \%$, and specificity of $60 \%$ as shown in Table 4 and Fig. 4.

Different examples of multiparametric MR studies in assessment of different renal cell carcinoma subtypes are presented in Figs. 5, 6, and 7.

\section{Discussion}

Our study aimed to determine if quantitative mpMRI data could be used as a non-invasive diagnostic imaging tool to differentiate renal cell carcinoma subtypes.
Surgery (partial or radical nephrectomy) remains the standard of care for young and healthy patients with incidentally found RCC. However, the substantial number of elderly patients with such tumors poses a clinical challenge, because rates of medical comorbidities and chances of renal impairment after surgery are generally higher among these patients [15]. This noninvasive quantitative mpMRI could prove clinically useful for treatment planning in elderly patients with comorbidities in whom biopsy or surgery is high risk, or to promote conservative treatment approaches such as active surveillance and focal ablation in eligible patients

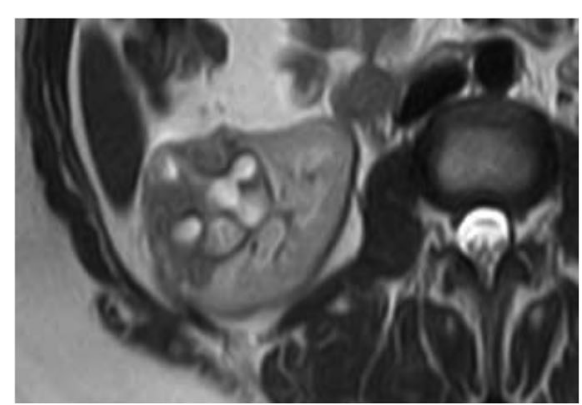

(A)

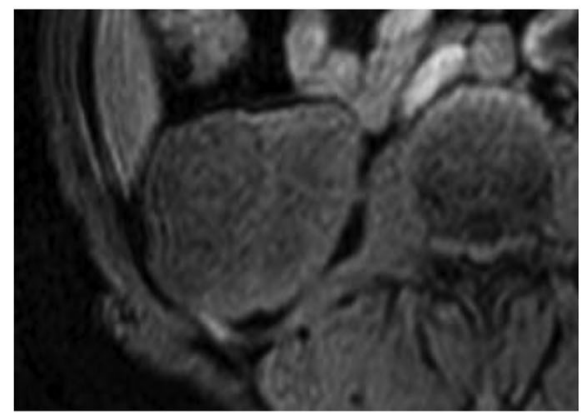

(B)

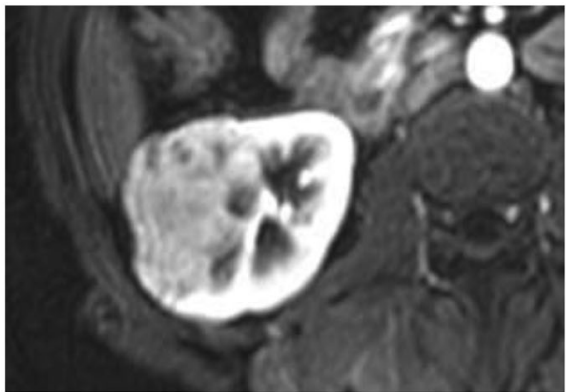

(C)

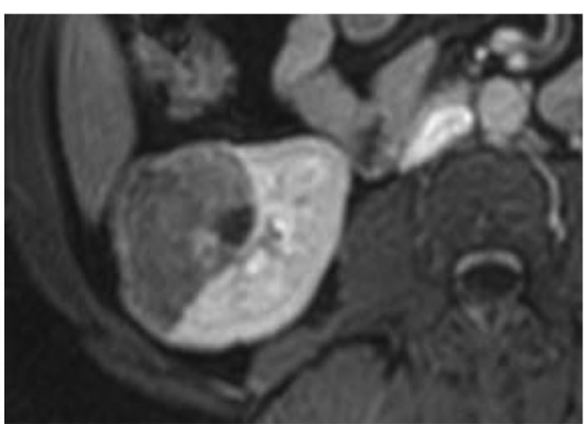

(D)

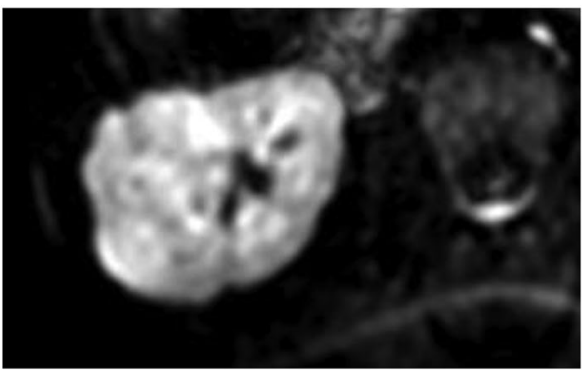

(E)

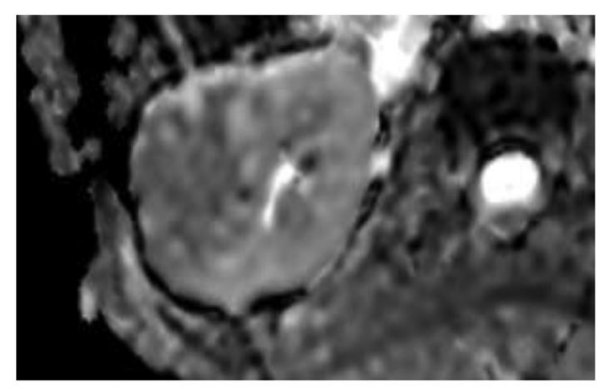

$(F)$

Fig. 5 Multiparametric MRI of cc-RCC. A case of right renal cc-RCC with small areas of necrosis, of a 30-year-old female. a Axial T2-WI shows the renal mass slightly lower SI compared with renal parenchyma. A ROI has been drawn and then reported on all sequences. Axial non-enhanced (b) and gadolinium-enhanced T1-W FS GRE-MR images in corticomedullary (c) and nephrographic (d) show early and intense heterogeneous enhancement of the solid components of the mass with washout at nephrographic phase. Axial DWI (b800mm²/s) (e) and ADC maps (f) show restricted signals corresponding the solid portion in the mass with ADC value $\left(1.3 \times 10^{-3} \mathrm{~mm}^{2} / \mathrm{s}\right)$ 


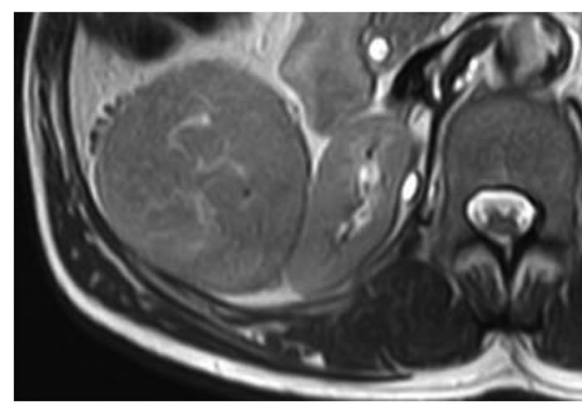

(A)

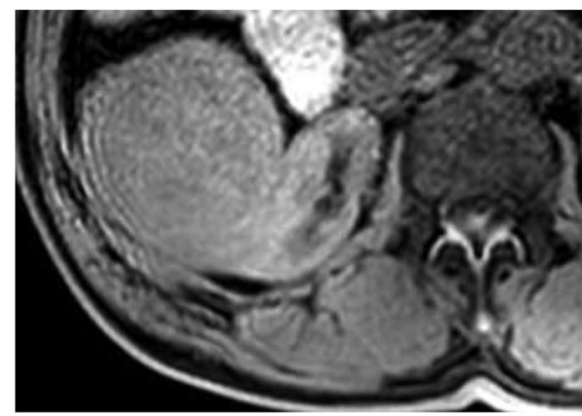

(B)

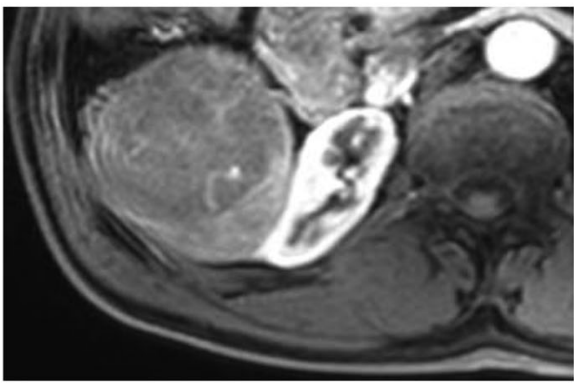

(C)

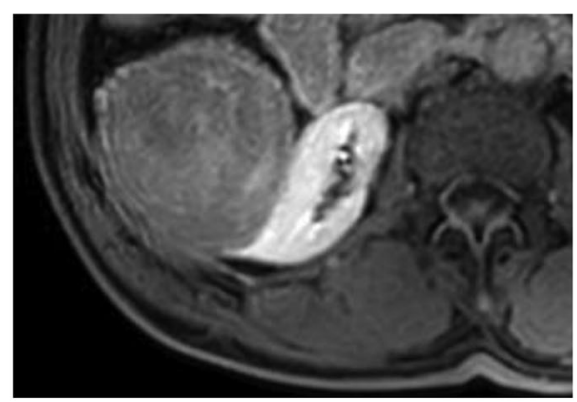

(D)

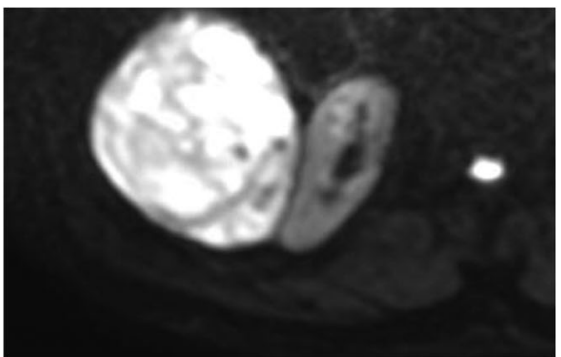

(E)

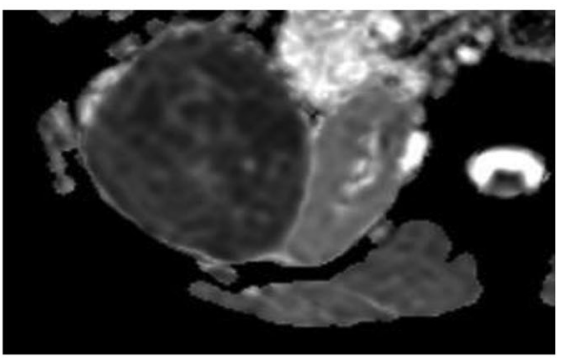

(F)

Fig. 6 Multiparametric MRI of cb-RCC. A case of cbRCC in the right kidney of a 60-year-old male. a Axial T2-W fast SE MR image shows the pronounced renal mass slightly lower SI compared with renal parenchyma. A ROI has been drawn and then reported on all sequences. Axial nonenhanced (b) and gadolinium-enhanced T1-W spoiled GRE-MR images in corticomedullary (c) and nephrographic (d) show early and moderate heterogeneous enhancement of the mass in corticomedullary and nephrographic phases. Axial DWI (b800 mm²/s) (e) and ADC maps (f) show restriction of diffusion into the renal mass with $A D C$ value $\left(1.1 \times 10^{-3} \mathrm{~mm}^{2} / \mathrm{s}\right)$

and is not part of the standard workup in most clinical centers [16].

To our knowledge, there are few published studies addressing the quantitative role of multiparametric MRI in the characterization of subtypes of renal cell carcinoma with no solid results till now, moreover most of these studies were conducted upon 1.5 tesla MRI machines, our clinical research was unique as it was done at 3 tesla MRI machine, also all our cases underwent surgical resection $o$ the mass with histopathological correlation.

Our analysis regarding the diagnostic value of different quantitative parameters of mpMRI in differentiation between different subtypes of renal cell carcinoma agreed with reported data of previous studies done by Cornelis et al. [1] and Yano et al. [17].

The mean ADC value for ccRCC $\left(1.56 \pm 0.27 \times 10^{-3}\right.$ $\left.\mathrm{mm}^{2} / \mathrm{s}\right)$ was significantly higher than that of pRCC $(0.96$ $\left.\pm 0.25 \times 10^{-3} \mathrm{~mm}^{2} / \mathrm{s}, P<0.001\right)$ and $\operatorname{cbRCC}(0.89 \pm 0.29$ $\left.\times 10^{-3} \mathrm{~mm}^{2} / \mathrm{s}, P<0.001\right)$. Similar to our results, Hassanen et al. reported that the mean ADC value of clear cell RCC $\left(1.789 \pm 0.5624 \times 10^{-3} \mathrm{~mm}^{2} / \mathrm{s}\right)$ was significantly higher $(P=0.0003)$ than that of both papillary RCC $\left(1.034 \pm 0.3411 \times 10^{-3} \mathrm{~mm}^{2} / \mathrm{s}\right)$ and chromophobe RCC $\left(1.19 \times 10^{-3} \mathrm{~mm}^{2} / \mathrm{s}\right)[18]$.

We found that the cutoff value of ADC in differentiation between clear cell RCC and non-clear cell RCC 


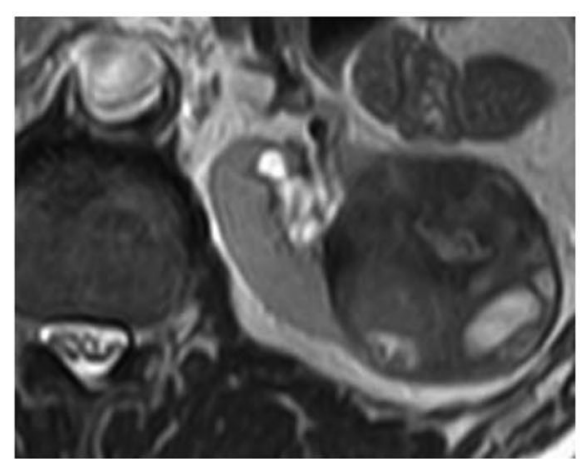

(A)

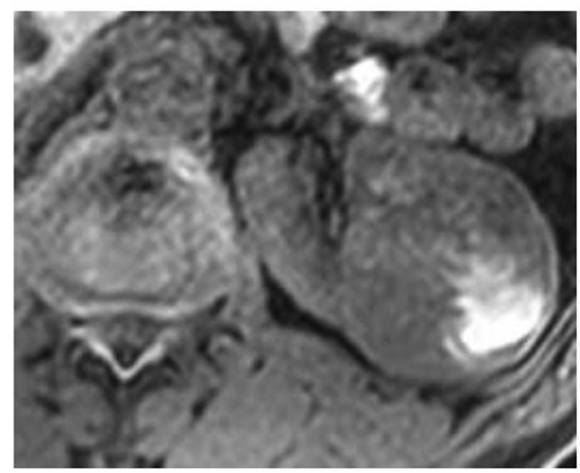

(B)

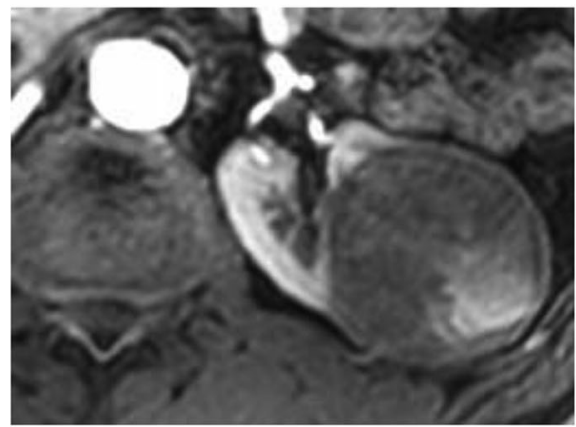

(C)

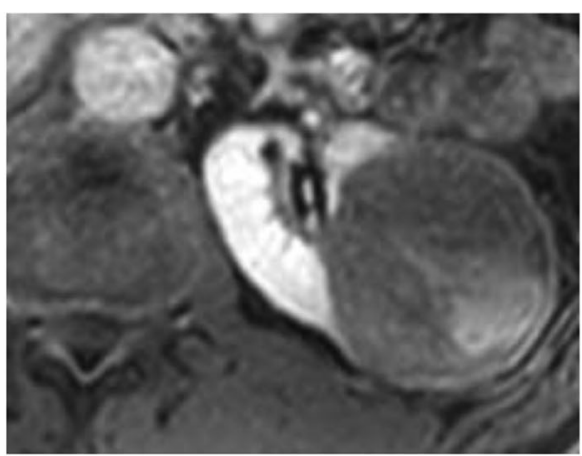

(D)

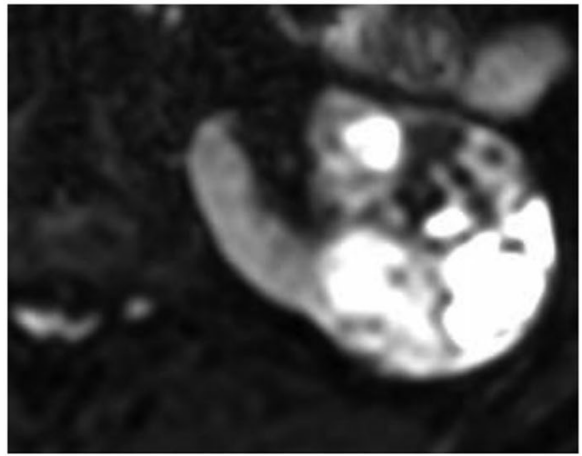

(E)

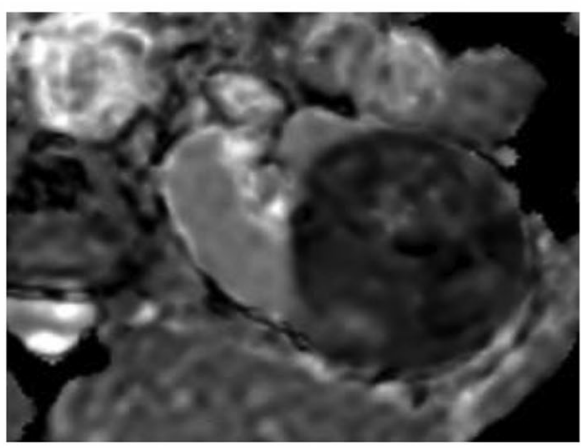

(F)

Fig. 7 Multiparametric MRI of p-RCC. A case of $p-R C C$ in the left kidney of a 63-year-old male. a Axial T2-W fast SE MR image shows the pronounced renal mass low SI compared with renal parenchyma with areas of high SI at T1-W and T2-W images indicating hemorrhagic component. Axial non-enhanced (b) and gadolinium-enhanced T1-W FS GRE-MR images in corticomedullary (c) and nephrographic (d) show slow and progressive enhancement of the mass with non-enhancing hemorrhagic component. Axial DWI (b800mm²/s) (e) and ADC maps (f) show marked restriction of diffusion in the renal mass with ADC value $\left(0.9 \times 10^{-3} \mathrm{~mm}^{2} / \mathrm{s}\right)$

was $1.35 \times 10^{-3} \mathrm{~mm}^{2} / \mathrm{s}$ with AUC of 0.936 , sensitivity of $91.7 \%$ and specificity of $76.7 \%$. This was in agreement with Hassanen et al. study who reported an ADC cutoff value of $1.309 \times 10^{-3} \mathrm{~mm}^{2} / \mathrm{s}$ for differentiation between the clear cell RCC and non-clear cell RCC with sensitivity of $79.17 \%$ and specificity of $78.57 \%$ [18].

In the current study, we detected that the mean ADC ratio for ccRCC $(0.75 \pm 0.13)$ was significantly higher than that of pRCC $(0.46 \pm 0.12, P<0.001)$ and cbRCC
$(0.41 \pm 0.15, P<0.001)$. However, the ADC ratio demonstrated no significant difference between $\mathrm{pRCC}$ and $\operatorname{cbRCC}(P=0.997)$.

We found also that the mean SII of pRCC was significantly higher than that of non-papillary RCC, in addition to demonstration of significant difference between ccRCC and cbRCC.

So, the clear cell RCC signal intensity index and ADC ratio is significantly different from those of 
other RCC, which was constant with the previous studies of Pedrosa et al., Karlo et al., Jhaveri et al., and Yano et al. [17, 19-21].

Contrary to Yano et al. study [17] regarding the absolute corticomedullary enhancement parameter, we found that it plays beneficial significant role in differentiation between ccRCC $(196.7 \pm 81.6)$ and nonclear subtypes of cbRCC $(177.8 \pm 77.7, P<0.001)$ and pRCC $(164.3 \pm 84.6, P<0.001)$; however it did not show significant difference between chromophobe and papillary subtype $(P=0.889)$, which was agreed with study of Cornelis et al. [2].

We found that $\mathrm{ADC}$ ratio had the best diagnostic performance (AUC $=0.938$ ) followed by Absolute CM Enhancement $(\mathrm{AUC}=0.937)$. However, SII showed lower diagnostic performance (AUC $=0.63$ ) compared to the other two parameters. Similar to our results, Cornelis et al. found that the diagnostic performance of early arterial tumor enhancement $(\mathrm{AUC}=0.93)$ and $\mathrm{ADC}$ ratio $(\mathrm{AUC}=$ 0.84 ) were higher than that of SII (AUC = 0.75) [2].

There are numerous clarifications for the discriminatory values paucity in characterization of solid renal lesions subtypes compared to others. No limit on lesion size was set in our study population, similar to other studies which were done for the same purpose as Cornelis et al., Mirka et al., Hötker et al., and Galmiche et al. $[2,22-24]$ without limits on lesion size, while contrary to Yano et al. who limited the study population to tumors $<3 \mathrm{~cm}$ [17] or Schieda et al. who studied lesions less than $4 \mathrm{~cm}$ in size [11].

We included large lesions more than $4 \mathrm{~cm}$ although MR characterization is more likely to be used with small renal masses less than $4 \mathrm{~cm}$ for which biopsy can be more challenging and where the prevalence of malignancy is lower. The selection of larger lesions in our study allow better evaluation of diffusion restriction and tissue enhancement; however, it led to variability in mpMRI quantitative results when compared to studies applied only on small renal masses.

In our study, the involved MRI evaluations were carried out on 3 tesla single-scanner rather than Yano et al. whose study was carried out on two $3 \mathrm{~T}$ scanners and one of eleven $1.5 \mathrm{~T}$ scanners [17]. We think that the studies having single-scanner are possibly more accurate and strong as they can adjust this variance.

In our study, we have number of limitations. First, it is relatively small sample size. Second, although our study was performed on a single-scanner and using a single contrast agent and that was potentially more robust because of controlling the variance. The scanners heterogeneity may actually be challenging the ability of application of the quantitative data of a single-scanner in the practice clinically; if the quantitative data are to be clinically utilized, it should able to be applied across several scanner platforms.

\section{Conclusion}

Our study demonstrated that multiparametric MRI is able to afford some quantitative features such as ADC ratio, SII, and absolute corticomedullary enhancement which can be used to accurately distinguish different subtypes of renal cell carcinoma. Also, our results support that the quantitative mpMRI is useful for differentiation between the clear cells RCC which is the most aggressive RCC subtype from other less aggressive ones and may play a clinically important value in treatment strategy and risk stratification of patients with renal tumors.

\section{Abbreviations \\ RCC: Renal cell carcinoma; ADC: Apparent diffusion coefficient; SIl: Signal intensity index; CCRCC: Clear cell renal cell carcinoma; PRCC: Papillary renal cell carcinoma; CbRCC: Chromophobe renal cell carcinoma; \\ MP: Multiparametric; DWI: Diffusion-weighted image; DCE: Dynamic contrast enhancement; IP: In phase; OP: Opposed phase; CSI: Chemical shift imaging; CE: Contrast enhancement; ROI: Region of interest; CM: Corticomedullary; NG: Nephrographic}

\section{Acknowledgements}

We acknowledge the members of the Radiology Department in Urology and Nephrology Center, Mansoura University (especially Prof. Tarek El-Diasty), and The Radiology Department in Mansoura University, Egypt.

\section{Authors' contributions}

MS and AE gave ideas and collected the patients' data and analyze them. MAE put study design and followed the patients postoperatively. HF and DB wrote the paper with revision. All authors read and approved the final manuscript.

\section{Funding}

This study had no funding from any resource.

\section{Availability of data and materials}

The datasets used and/or analyzed during the current study are available from the corresponding author on reasonable request.

\section{Ethics approval and consent to participate}

This study was approved by the Research Ethics Committee of the Faculty of Medicine at Mansoura University in Egypt on 20 August 2017; reference number of approval: MS/17.08.75.

\section{Consent for publication}

All patients included in this research gave written informed consent to publish the data contained within this study.

\section{Competing interests}

The authors declare that they have no competing interests.

\section{Author details}

'Radiology Departments, Urology and Nephrology Center, Mansoura University, Mansoura, Egypt. ${ }^{2}$ Radiology Department, Faculty of Medicine, Mansoura University, Mansoura, Egypt.

Received: 23 November 2020 Accepted: 28 December 2020 Published online: 05 February 2021

\section{References}

1. Cornelis F, Grenier N (2017) Multiparametric magnetic resonance imaging of solid renal tumors: a practical algorithm. Seminars Ultrasound, CT MRI 38(1):47-58

2. Cornelis F, Tricaud E, Lasserre A, Petitpierre F, Bernhard J, Le Bras $Y$ et al (2014) Routinely performed multiparametric magnetic resonance imaging helps to differentiate common subtypes of renal tumours. Eur Radiol 24(5): 1068-1080 
3. Lopes Vendrami C, Parada Villavicencio C, DeJulio TJ, Chatterjee A, Casalino DD, Horowitz JM et al (2017) Differentiation of solid renal tumors with multiparametric MR imaging. Radiographics. 37(7):2026-2042

4. De Silva S, Lockhart K, Aslan P, Nash P, Hutton A, Malouf D, et al. (2020). Chemical shift imaging in the identification of those renal tumors that contain microscopic fat and the utility of multiparametric MRI in their differentiation. J Med Imaging Radiat Oncol. 64(6): 762-768.

5. Adam SZ, Nikolaidis P, Horowitz JM, Gabriel H, Hammond NA, Patel T et al (2016) Chemical shift MR imaging of the adrenal gland: principles, pitfalls, and applications. Radiographics. 36(2):414-432

6. Ramamurthy N, Moosavi B, Mclnnes M, Flood T, Schieda N (2015) Multiparametric MRI of solid renal masses: pearls and pitfalls. Clin Radiol 70(3):304-316

7. Wu Y, Kwon YS, Labib M, Foran DJ, Singer EA. (2015). Magnetic resonance imaging as a biomarker for renal cell carcinoma. Disease markers. 2015:1-9.

8. Canvasser NE, Kay FU, Xi Y, Pinho DF, Costa D, de Leon AD et al (2017) Diagnostic accuracy of multiparametric magnetic resonance imaging to identify clear cell renal cell carcinoma in CT1a renal masses. J Urol 198(4): 780-786

9. Choi YA, Kim CK, Park SY, Cho SW, Park BK (2014) Subtype differentiation of renal cell carcinoma using diffusion-weighted and blood oxygenation leveldependent MRI. Am J Roentgenol 203(1):W78-W84

10. Mittal MK, Sureka B (2016) Solid renal masses in adults. Indian J Radiol Imaging 26(4):429

11. Schieda N, Dilauro M, Moosavi B, Hodgdon T, Cron GO, Mclnnes MD et al (2016) MRI evaluation of small $(<4 \mathrm{~cm})$ solid renal masses: multivariate modeling improves diagnostic accuracy for angiomyolipoma without visible fat compared to univariate analysis. Eur Radiol 26(7):2242-2251

12. Young JR, Coy H, Kim HJ, Douek M, Lo P, Pantuck AJ et al (2017) Performance of relative enhancement on multiphasic MRI for the differentiation of clear cell renal cell carcinoma (RCC) from papillary and chromophobe RCC subtypes and oncocytoma. Am J Roentgenol 208(4): 812-819

13. Galia M, Albano D, Bruno A, Agrusa A, Romano G, Di Buono G et al (2017) Imaging features of solid renal masses. Br J Radiol 90(0):20170077

14. Khatri G, Pedrosa IM (2012) 3 T MR imaging protocol for characterization of renal masses. Appl Radiol 41(Suppl):22-26

15. Wang ZJ, Westphalen AC, Zagoria RJ (2018) CT and MRI of small renal masses. Br J Radiol 91(1087):20180131

16. Hötker AM, Mazaheri Y, Wibmer A, Karlo CA, Zheng J, Moskowitz CS et al (2017) Differentiation of clear cell renal cell carcinoma from other renal cortical tumors by use of a quantitative multiparametric MRI approach. Am J Roentgenol 208(3):W85-W91

17. Yano M, Fowler KJ, Srisuwan S, Salter A, Siegel CL (2018) Quantitative multiparametric MR analysis of small renal lesions: correlation with surgical pathology. Abdominal Radiol 43(12):3390-3399

18. Hassanen O, Ghieda U, Eltomey MA (2017) Contrast enhanced MRI and diffusion weighted imaging (DWI) in the evaluation of renal cell carcinoma and differentiation of its subtypes. Egypt J Radiol Nuclear Med 48(4):1117-1123

19. Pedrosa I, Sun MR, Spencer M, Genega EM, Olumi AF, Dewolf WC et a (2008) MR imaging of renal masses: correlation with findings at surgery and pathologic analysis. Radiographics. 28(4):985-1003

20. Jhaveri KS, Elmi A, Hosseini-Nik H, Hedgire S, Evans A, Jewett M et al (2015) Predictive value of chemical-shift MRI in distinguishing clear cell renal cell carcinoma from non-clear cell renal cell carcinoma and minimal-fat angiomyolipoma. Am J Roentgenol 205(1):W79-W86

21. Karlo CA, Donati OF, Burger IA, Zheng J, Moskowitz CS, Hricak H et al (2013) MR imaging of renal cortical tumours: qualitative and quantitative chemical shift imaging parameters. Eur Radiol 23(6):1738-1744

22. Galmiche C, Bernhard J-C, Yacoub M, Ravaud A, Grenier N, Cornelis F (2017) Is multiparametric MRI useful for differentiating oncocytomas from chromophobe renal cell carcinomas? Am J Roentgenol 208(2):343-350

23. Mirka H, Korcakova E, Kastner J, Hora M, Hes O, Hosek P et al (2015) Diffusion-weighted imaging using 3.0 T MRI as a possible biomarker of renal tumors. Anticancer Res 35(4):2351-2357

24. Hötker AM, Mazaheri Y, Wibmer A, Zheng J, Moskowitz CS, Tickoo SK et al (2016) Use of DWI in the differentiation of renal cortical tumors. Am J Roentgenol 206(1):100-105

\section{Publisher's Note}

Springer Nature remains neutral with regard to jurisdictional claims in published maps and institutional affiliations.

\section{Submit your manuscript to a SpringerOpen ${ }^{\circ}$ journal and benefit from:}

- Convenient online submission

- Rigorous peer review

- Open access: articles freely available online

- High visibility within the field

- Retaining the copyright to your article

Submit your next manuscript at $\boldsymbol{\nabla}$ springeropen.com 